\title{
TREATMENT OF VERTEBRAL PATHOLOGICAL FRACTURES BY PERCUTANEOUS VERTEBROPLASTY
}

\author{
TRATAMENTO DAS FRATURAS VERTEBRAIS PATOLÓGICAS POR VERTEBROPLASTIA PERCUTÂNEA \\ TRATAMIENTO DE FRACTURAS VERTEBRALES PATOLÓGICAS POR VERTEBROPLASTIA PERCUTÁNEA
}

Rodrigo D'Alessandro de Macedo ${ }^{1}$, Kleber Miranda Linhares ${ }^{1}$

\begin{abstract}
Objective: To evaluate a consecutive series of patients undergoing vertebroplasty for pain control, according to results and complications in the short and medium follow-up. Methods: Retrospective analysis of medical records of 26 patients undergoing vertebroplasty from January 2007 to December 2010. Patients were evaluated by the questionnaire of assessment of low back pain (Oswestry Index) and the visual analog pain scale (VAS) on the day before surgery, on the second day and 12 months after the procedure. Results: Significant improvement of pain symptoms within 48 hours after surgery was reported in 22 patients (91.6\%), two patients (8.32\%) showed moderate improvement. Of the 22 patients with significant pain relief, 21 (95.4\%) maintained the benefit and one (4.6\%) had intense pain (new fracture in the body of L1) at a mean follow up of 12 months. Regarding the Oswestry Index, preoperative average was $52.9 \%$. On the second day and 12 months after surgery this average was $23.6 \%$ and $24.5 \%$, respectively; good results according to this index. Two patients were excluded from the study due to incomplete medical records. Conclusion: Despite the small sample size and short follow-up, the results of vertebroplasty were effective for the relief of pain symptoms and were safe as regards the risks of complications.
\end{abstract}

Keywords: Low back pain; Spinal fractures; Osteoporosis; Vertebroplasty; Retrospective studies.

\section{RESUMO}

Objetivo: Avaliar uma série consecutiva de pacientes submetidos à vertebroplastia para controle álgico, segundo seus resultados e complicações em curto e médio seguimento. Métodos: Análise retrospectiva de prontuários de 26 pacientes submetidos à vertebroplastia entre janeiro de 2007 e dezembro de 2010. Os pacientes foram submetidos ao questionário de avaliação da lombalgia (Índice de Oswestry) e à escala visual analógica de dor (EVA) no dia anterior ao procedimento cirúrgico, no segundo dia e 12 meses após o procedimento. Resultados: Melhora acentuada do quadro álgico em 48 horas de pós-operatório foi relatada em 22 pacientes (91,6\%), dois pacientes (8,32\%) apresentaram melhora moderada. Dos 22 pacientes com alívio significativo da dor, 21 (95,4\%) mantiveram o benefício e um (4,6\%) apresentou quadro álgico intenso (nova fratura no corpo de L1) no seguimento médio de 12 meses. Com relação ao Índice de Oswestry, a média pré-operatória obtida foi 52,9\%. No segundo dia e após 12 meses, foi 23,6\% e 24,5\% respectivamente, bons resultados segundo esse índice. Dois pacientes foram excluídos do estudo devido ao preenchimento incompleto do prontuário. Conclusão: Apesar da pequena casuística e do curto seguimento, os resultados da vertebroplastia mostraram-se eficazes quanto ao alívio dos sintomas álgicos e seguros quanto aos riscos de complicações.

Descritores: Dor lombar; Fraturas da coluna vertebral; Osteoporose; Vertebroplastia; Estudos retrospectivos.

\section{RESUMEN}

Objetivo: Evaluar una serie consecutiva de pacientes sometidos a vertebroplastia para controlar el dolor, de acuerdo con los resultados y las complicaciones a corto y medio seguimiento. Métodos: Análisis retrospectivo de las historias clínicas de 26 pacientes sometidos a vertebroplastia entre enero de 2007 y diciembre de 2010. Los pacientes fueron sometidos al cuestionario de evaluación de lumbalgia (Índice de Oswestry) y la escala analógica visual de dolor (EVA) el día antes de la cirugía, en el segundo día y 12 meses después del procedimiento. Resultados: Una marcada mejoría de los síntomas de dolor en las 48 horas de postoperatorio se informó en 22 pacientes (91,6\%), dos pacientes (8,32\%) mostraron una mejoría moderada. De los 22 pacientes con un alivio significativo del dolor, 21 (95,4\%) mantuvieron el beneficio y uno (4,6 \%) tenía dolor intenso (nueva fractura en el cuerpo de L1) con un seguimiento medio de 12 meses. En cuanto al Índice de Oswestry, el promedio preoperatorio fue del 52,9\%. En el segundo día, y después de 12 meses fue de 23,6\% y 24,5\%, respectivamente; buenos resultados de acuerdo a este índice. Dos pacientes fueron excluidos del estudio, debido a los registros médicos incompletos. Conclusión: A pesar del pequeño tamaño de la muestra y el corto período de seguimiento, los resultados de la vertebroplastia fueron satisfactorios en cuanto al alivio de los síntomas de dolor y seguros cuando se refiere a los riesgos de complicaciones.

Descriptores: Dolor de la región lumbar; Fracturas de la columna vertebral; Osteoporosis; Vertebroplastia, Estudios retrospectivos.

1. Hospital da Baleia, Belo Horizonte, MG, Brazil.

Study conducted at the Instituto de Previdência dos Servidores do Estado de Minas Gerais and at the Hospital da Baleia, Belo Horizonte, MG, Brazil. Correspondence: Kleber Miranda Linhares. Rua São Paulo, 1755, apto 1301, Lourdes. Belo Horizonte, MG, Brasil. 30170-132. kmlinhares@ gmail.com 


\section{INTRODUCTION}

Approximately 438,750 vertebral fractures are diagnosed in Europe each year. ${ }^{1}$ The main cause of pathological fractures of the vertebral body is primary osteoporosis (85\%), while the remaining $15 \%$ are secondary to malignant disease (primary metastatic disease). ${ }^{2}$ Vertebral fractures are often misdiagnosed, are more common, and affect patients earlier than any other osteoporotic fracture (such as hip fractures). ${ }^{3}$ Clinical symptoms include back pain, limited spinal movement, loss of vertebral body height, and deformity. These symptoms reduce physical efficiency and negatively affect the quality of life due to a higher occurrence of social isolation. ${ }^{4,5}$

Around 500,000 vertebral compression fractures and 250,000 fractures in the hip region due to osteoporosis occur annually. The three most common locations for osteoporotic fractures are the distal end of the bones of the forearm, the spine, and the proximal region of the femur. ${ }^{6}$

Thirty years ago, the only treatments available for vertebral compression fractures were the use of analgesics, rest, and a spinal brace. Approximately $1 / 3$ of the patients with vertebral compression fractures do not respond to conventional conservative treatments, leading to prolonged periods of inactivity, increasing the loss of bone mass and the risk of new fractures. ${ }^{7}$

Percutaneous vertebroplasty (PV) is a minimally invasive interventional radiological procedure that consists of an injection of polymethylmethacrylate (PMMA) biomaterial into the interior of the fractured vertebral body to reduce pain and increase the resistance of the vertebral body. ${ }^{8}$ This procedure was initially described in $1984,{ }^{9}$ in France, for the treatment of hemangiomas of the vertebral body and published by Galibert et al ${ }^{10}$ The indications were then expanded to include other injuries affecting the vertebrae, such as osteoporotic fractures, myelomas, and metastatic lesions. ${ }^{8,9,11}$

Percutaneous vertebroplasty, although its pain improvement mechanism has not been defined, whether due to the heat released by the bone cement that has a cauterizing effect on the nerve ends of the vertebral bodies, or as a result of the stabilization of the vertebral body preventing microfractures, has surprising results both for pain relief and the stabilization of the vertebral body. ${ }^{12-14}$

Biomechanical tests have shown that PV generally restores or increases the strength and rigidity of the vertebral body compared to pre-fracture values and probably provides an internal splint that prevents local movement of the fracture. ${ }^{15,16}$ However, the pain relief action mechanism is still unknown. ${ }^{17}$

Osteoporotic vertebral fractures cause not only pain, but also spinal misalignment, especially kyphosis. Kyphosis of the thoracic spine, in turn, causes deformity of the rib cage. Therefore, osteoporotic fractures reduce activities of daily living, cause respiratory dysfunction, and increase the prevalence of lung disease. Mortality rates in women with osteoporosis clinically diagnosed with vertebral fractures are 15\% higher than in those without fractures. Additionally, mortality rates are $23-24 \%$ higher in osteoporotic women with multiple serious fractures or kyphosis than in those without these conditions, and are directly related to impaired lung function as a result of thoracic and lumbar spinal fractures. ${ }^{18}$

The objective of this study was to evaluate a consecutive series of patients who underwent vertebroplasty for pain control, using both the Oswestry Index and the visual analog pain scale, as well as the short- and long-term outcomes and complications.

\section{PATIENTS AND METHODS}

A retrospective study was conducted, following approval by the Research Ethics Committee of the Hospital da Baleia, MG, Brazil, opinion number 367,571 issued on $07 / 17 / 2013$, analyzing the scores of 24 patients who underwent vertebroplasty, after six to eight weeks of conservative treatment following the diagnosis, during the period January 2007 to December 2010. Anteroposterior and profile radiographies of the thoracolumbar spine were taken of all patients, followed by magnetic resonance studies to rule out other pathologies. The average age was 65.4 years, ranging from 40 to 74 . There were 22 women $(91.66 \%)$ and two men (8.33\%). In terms of the underlying disease, 22 (91.66\%) had pathological vertebral fractures secondary to osteoporosis and two (8.33\%) had fractures resulting from metastases (the primary focus of which was the prostate). All patients had previously signed an informed consent form.

The distribution by level of the fractured vertebrae, sex, age, and etiology is presented in Table 1.

The indication of vertebroplasty was consistent with the medical literature, with the following inclusion criteria: the vertebral body must have maintained at least $1 / 3$ of its original height; serious and incapacitating pain resistant to analgesics for six to eight weeks; progression of deformity; and increasing pain as a result of osteolytic lesions of the vertebral body.

The procedure is contraindicated in the presence of infection and uncompensated clotting disorders. Additional care should be taken when treating patients with neoplastic diseases that cause destruction of the posterior wall of the vertebral body, due to the high risk of complications. ${ }^{19}$

Table 1. Distribution by sex: female (F) and male (M)

\begin{tabular}{|c|c|c|c|c|}
\hline Identification & Fractured Vertebra & Sex & Age & Etiology \\
\hline 1 & L1 & $\mathrm{F}$ & 63 & Osteoporosis \\
\hline 2 & L1 & $\mathrm{F}$ & 74 & Osteoporosis \\
\hline 3 & L1 & $\mathrm{F}$ & 40 & Osteoporosis \\
\hline 4 & L1 & $\mathrm{F}$ & 69 & Osteoporosis \\
\hline 5 & L1 & $\mathrm{F}$ & 69 & Osteoporosis \\
\hline 6 & L1 & $\mathrm{F}$ & 71 & Osteoporosis \\
\hline 7 & L3 & $\mathrm{F}$ & 66 & Osteoporosis \\
\hline 8 & L3 & $\mathrm{F}$ & 65 & Osteoporosis \\
\hline 9 & L3 & $\mathrm{F}$ & 57 & Osteoporosis \\
\hline 10 & L3 & $\mathrm{F}$ & 68 & Osteoporosis \\
\hline 11 & T8 & $\mathrm{F}$ & 69 & Osteoporosis \\
\hline 12 & T8 & $\mathrm{F}$ & 74 & Osteoporosis \\
\hline 13 & T8 & $\mathrm{F}$ & 50 & Osteoporosis \\
\hline 14 & $\mathrm{~T} 11$ & $\mathrm{~F}$ & 58 & Osteoporosis \\
\hline 15 & $\mathrm{~T} 11$ & $\mathrm{~F}$ & 63 & Osteoporosis \\
\hline 16 & L5 & $\mathrm{F}$ & 66 & Osteoporosis \\
\hline 17 & L5 & $\mathrm{F}$ & 80 & Osteoporosis \\
\hline 18 & $\mathrm{~T} 12$ & $\mathrm{~F}$ & 64 & Osteoporosis \\
\hline 19 & $\mathrm{~T} 12$ & $\mathrm{~F}$ & 71 & Osteoporosis \\
\hline 20 & $\mathrm{~T} 10, \mathrm{~T} 12$ & $\mathrm{~F}$ & 69 & Osteoporosis \\
\hline 21 & T9, T10, L1 & $\mathrm{F}$ & 70 & Osteoporosis \\
\hline 22 & T10, T12, L2, L4 & $\mathrm{F}$ & 59 & Osteoporosis \\
\hline 23 & $\mathrm{~T} 10$ & $\mathrm{M}$ & 69 & Tumor \\
\hline 24 & $\mathrm{~T} 12$ & M & 67 & Tumor \\
\hline
\end{tabular}

SOURCE: Data compiled by the author.

\section{Surgical Technique}

Vertebroplasties were performed in the ventral decubitus position under sedation and local anesthesia. The vertebra and the area corresponding to the pedicle were identified under radioscopy in the AP view and then marked in the transversal and longitudinal directions, dividing the image of the pedicle into four roughly equal parts. An incision was made 1 to $3 \mathrm{~cm}$ below the transversal line from the center of the pedicle to the lateral. Immediately afterwards, a $2 \mathrm{~mm}$ Kirschner guidewire was introduced as far as the cortical rim in the superolateral quadrant, using a hammer, introducing the 
wire at an angle of approximately $45^{\circ}$. The wire must be positioned under radioscopic control in the AP and profile views.

Next, after proper positioning of the guidewire (around $1 / 2$ body in $\mathrm{AP}$ and $1 / 2$ to $3 / 4$ in profile), the cannula and trocar are positioned in the vertebral body. (Figure 1) Approximately 2.5 to $5.0 \mathrm{~mm}^{3}$ of semi-liquid material (polymethylmethacrylate) is injected into each vertebral body under radioscopic control in the profile view, enabling identification of an undesirable injection of material into the epidural space or anterior to the vertebral body.

Figure 2 shows the inoculation of PMMA combined with radiopaque material (barium).

The postoperative protocol includes bed rest for three hours, after which the patient can sit up, or walk. The patient is discharged the next day (24 hours), with outpatient follow-up. Patients were evaluated on the day prior to the surgical procedure, the second day (48 hours) following surgery, and 12 months into the postoperative period, using the Visual Analog Scale (VAS), in which pain is graded from zero to ten, with the lowest value indicating the absence of pain and the highest the most intense pain, and the Oswestry Index, a questionnaire to assess low back pain. The Oswestry Index considers pain intensity and asks different questions about the quality of life (locomotion ability, social life, quality of sleep, and sex life). The patients were also assessed in relation to the frequency of pain crises and the need to use analgesics.

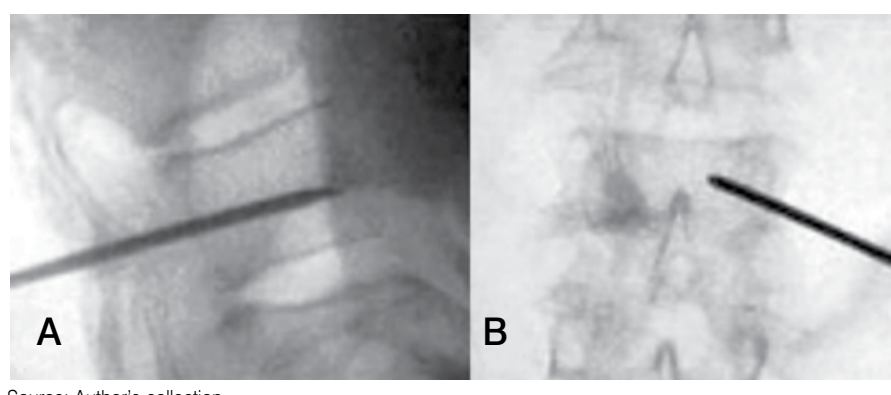

Figure 1. Positioning of the cannula, in a cadaver, guided by radioscope: (A) profile view; (B) anteroposterior view.

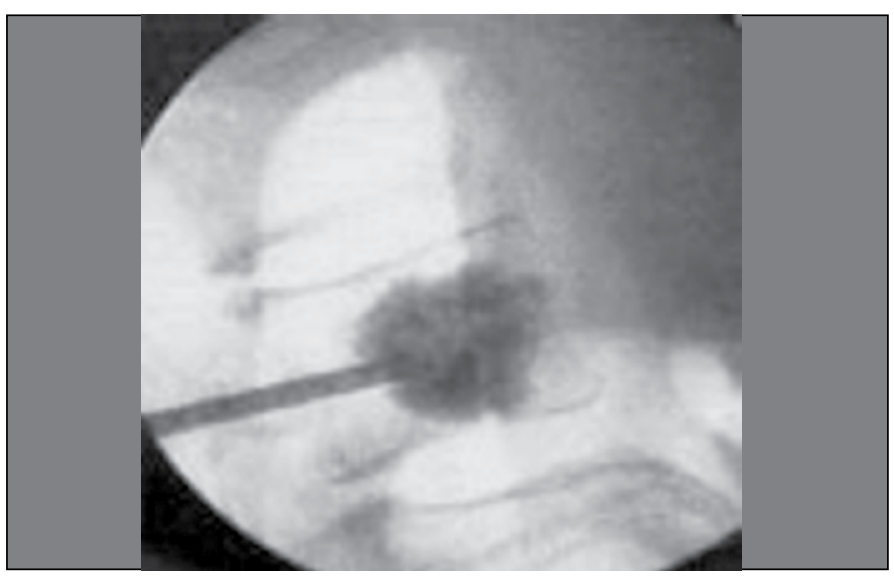

Source: Author's collection.

Figure 2. PMMA inoculation in a cadaver.

\section{RESULTS}

A marked improvement in the pain profile was reported 48 hours after surgery by $22(91.6 \%)$ patients and two (8.32\%) reported moderate improvement. Of the 22 patients with significant pain relief, 21 $(95.4 \%)$ maintained the benefit in the medium term and one $(4.6 \%)$ presented a profile of intense pain (patient with a new fracture in the L1 vertebral body) in the medium term, at 12 months. The frequency of pain crises was reduced in $91.67 \%$ of the interviewees. All the patients reported an improvement in quality of sleep, an increase in the length of time they could remain standing or walk without pain, and an improved sex life (where applicable). The use of analgesics was lower in all patients (100\%). Of a total of 18 patients who reported daily use of analgesics prior to PV, 15 stopped completely and three only used them occasionally (monthly). All patients reported that they would undergo vertebroplasty again if needed. There were no complications related to percutaneous access, PMMA injection, or the worsening of clinical conditions in the patients who underwent PV.

The average preoperative Oswestry Index score obtained was $52.9 \%$. The two-day and 12-month postoperative averages were $23.6 \%$ and $24.5 \%$, respectively. Based on an interpretation of the figures from this low back pain evaluation questionnaire, the result was good

Table 2 shows the results measured by the Oswestry questionnaire in the preoperative, immediate postoperative (2 days), and late postoperative (12 months) periods.

Table 2. Results measured by the Oswestry questionnaire in the preoperative, immediate postoperative (2 days), and late postoperative (12 months) periods.

\begin{tabular}{|c|c|c|c|}
\hline Identification & Preoperative & $\begin{array}{l}\text { Postoperative } \\
\text { (2 Days) }\end{array}$ & $\begin{array}{l}\text { Postoperative } \\
\text { (12 months) }\end{array}$ \\
\hline (12 months) & $55.50 \%$ & $22.20 \%$ & $22.20 \%$ \\
\hline 2 & $48.80 \%$ & $22.20 \%$ & $24.40 \%$ \\
\hline 3 & $36 \%$ & $18 \%$ & $20 \%$ \\
\hline 4 & $62.20 \%$ & $37.70 \%$ & $21.20 \%$ \\
\hline 5 & $46.60 \%$ & $24.40 \%$ & $18 \%$ \\
\hline 6 & $42.20 \%$ & $20 \%$ & $17.70 \%$ \\
\hline 7 & $52 \%$ & $22 \%$ & $20 \%$ \\
\hline 8 & $64 \%$ & $20 \%$ & $24.40 \%$ \\
\hline 9 & $44 \%$ & $18 \%$ & $18 \%$ \\
\hline 10 & $60 \%$ & $40 \%$ & $37.70 \%$ \\
\hline 11 & $60 \%$ & $35.50 \%$ & $33.30 \%$ \\
\hline 12 & $62.20 \%$ & $33.30 \%$ & $31 \%$ \\
\hline 13 & $50 \%$ & $18 \%$ & $22 \%$ \\
\hline 14 & $42.20 \%$ & $24.40 \%$ & $62.20 \%$ \\
\hline 15 & $55.50 \%$ & $22.20 \%$ & $20 \%$ \\
\hline 16 & $52 \%$ & $22 \%$ & $18 \%$ \\
\hline 17 & $57.70 \%$ & $33.30 \%$ & $31 \%$ \\
\hline 18 & $56 \%$ & $14 \%$ & $14 \%$ \\
\hline 19 & $48.80 \%$ & $20 \%$ & $22 \%$ \\
\hline 20 & $42.20 \%$ & $17.70 \%$ & $18 \%$ \\
\hline 21 & $62.20 \%$ & $31.10 \%$ & $36 \%$ \\
\hline 22 & $62.20 \%$ & $28.80 \%$ & $33.30 \%$ \\
\hline 23 & $53.30 \%$ & $8 \%$ & $8 \%$ \\
\hline 24 & $54 \%$ & $14 \%$ & $17.70 \%$ \\
\hline AVERAGE & $52.90 \%$ & $23.60 \%$ & $24.50 \%$ \\
\hline
\end{tabular}

SOURCE: Data compiled by the author. 
The VAS yielded an average of 8.64 preoperatively (PO), decreasing to 2.5 on the second day of the postoperative period (Pop 2), and to 1.68 points at 12 months postoperative (Pop 12). Accordingly, an average pain reduction of $71 \%$ was obtained between $\mathrm{PO}$ and Pop 2, and of $81 \%$ between PO and Pop 12 . However, rates of $33 \%$ between PO and Pop 2 and $56 \%$ between $\mathrm{PO}$ and Pop 12 were obtained for one patient, which are considered low compared to those obtained for the other patients.

Table 3 shows the results obtained in the VAS.

Table 3. Results obtained from the VAS in the preoperative, immediate postoperative (2 days), and late postoperative (12 months) periods.

\begin{tabular}{|c|c|c|c|c|c|}
\hline Identification & Preop. & $\begin{array}{l}\text { Postop. } \\
\text { (2 Days) }\end{array}$ & $\begin{array}{l}\text { Postop. } \\
\text { (12 } \\
\text { Months) }\end{array}$ & $\begin{array}{c}\text { (\%) Pain } \\
\text { reduction } \\
\text { between preop. } \\
\text { and postop. } \\
\text { (2 days) }\end{array}$ & $\begin{array}{c}\text { (\%) Pain } \\
\text { reduction } \\
\text { between preoper. } \\
\text { and postop. } \\
\text { (12 months) }\end{array}$ \\
\hline 1 & 8 & 3 & 1 & $63 \%$ & $88 \%$ \\
\hline 2 & 7 & 3 & 1 & $57 \%$ & $86 \%$ \\
\hline 3 & 6 & 2 & 1 & $67 \%$ & $83 \%$ \\
\hline 4 & 9 & 4 & 1 & $56 \%$ & $89 \%$ \\
\hline 5 & 7 & 3 & 1 & $57 \%$ & $86 \%$ \\
\hline 6 & 7 & 2 & 1 & $71 \%$ & $86 \%$ \\
\hline 7 & 8 & 3 & 2 & $63 \%$ & $75 \%$ \\
\hline 8 & 9 & 2 & 1 & $78 \%$ & $89 \%$ \\
\hline 9 & 7 & 2 & 1 & $71 \%$ & $86 \%$ \\
\hline 10 & 9 & 6 & 4 & $33 \%$ & $56 \%$ \\
\hline 11 & 9 & 4 & 2 & $56 \%$ & $78 \%$ \\
\hline 12 & 9 & 4 & 3 & $56 \%$ & $67 \%$ \\
\hline 13 & 8 & 1 & 2 & $88 \%$ & $75 \%$ \\
\hline 14 & 7 & 2 & 2 & $71 \%$ & $71 \%$ \\
\hline 15 & 8 & 2 & 1 & $75 \%$ & $88 \%$ \\
\hline 16 & 8 & 1 & 1 & $88 \%$ & $88 \%$ \\
\hline 17 & 8 & 2 & 2 & $75 \%$ & $75 \%$ \\
\hline 18 & 8 & 1 & 1 & $88 \%$ & $88 \%$ \\
\hline 19 & 7 & 1 & 2 & $86 \%$ & $71 \%$ \\
\hline 20 & 7 & 1 & 1 & $86 \%$ & $86 \%$ \\
\hline 21 & 9 & 2 & 2 & $78 \%$ & $78 \%$ \\
\hline 22 & 9 & 1 & 2 & $89 \%$ & $78 \%$ \\
\hline 23 & 8 & 2 & 1 & $75 \%$ & $88 \%$ \\
\hline 24 & 8 & 1 & 1 & $88 \%$ & $88 \%$ \\
\hline AVERAGE & 8,64 & 2,50 & 1,68 & $71 \%$ & $81 \%$ \\
\hline
\end{tabular}

SOURCE: Data compiled by the author.

\section{DISCUSSION}

For many years, the treatment protocol for vertebral fractures from osteoporosis was limited to several weeks of bed rest, the use of anti-inflammatories and analgesics, the use of calcitonin, and external immobilization. Currently, there are techniques for filling fractured vertebral bodies resistant to conservative treatment with bone cement. ${ }^{20}$

Recent retrospective and prospective studies with significant numbers of patients clearly show the efficacy and the duration of the analgesic effect of this therapeutic technique.21-24

Amar et al published a study with a total of 97 patients with osteoporotic fractures and osteolytic neoplasias who had undergone PV. ${ }^{11,14}$ The average age was 76 years. The use of analgesic medications was reduced in $63 \%$ of the patients, increased in $7 \%$, and unchanged in 30\%. Walking and mobility improved in 51\%, worsened in $1 \%$, and remained unchanged in $48 \%$. Around $74 \%$ of the patients reported improvements in their quality of life, while $26 \%$ did not notice any improvement. None reported a worsening of their situation. One patient with prior pneumonia died following the procedure and another died from a stroke weeks after the PV. Three patients presented pulmonary embolisms from the cement, but without any clinical repercussions. Leakage of the PMMA into the neuroforamen occurred in three patients and into the peridural space in four patients. There was no neurological deficit in any of these cases, and they were treated clinically. There was one case of dural laceration caused by the trochanter, which closed spontaneously. There were no late complications related to the PV. ${ }^{11}$

Hochmuth et $\mathrm{a}^{25}$, in a review article comprising more than 2000 patients, concluded that the rate of serious symptomatic complications was less than $1 \%$ in patients who had undergone PV.

Pizzoli et a/26 published a series with 182 vertebroplasties performed on 106 patients, 67 with osteoporotic vertebral fractures and 39 with metastases. The patients with osteoporosis underwent $120 \mathrm{PVs}, 77.5 \%$ of which were in the lumbar spine. The patients with metastases underwent $62 \mathrm{PVs}, 56.4 \%$ of which were in the thoracic spine. Total or partial pain relief was achieved in $98 \%$ of the patients within 24 hours following treatment. Significant results in terms of improvements in functional mobility and reduction of the use of analgesics were also obtained. Serious complications included one case of pneumothorax and two symptomatic cases of cement leakage. Minor complications included two cases of pulmonary embolism from the cement, which recovered without any procedures. During follow-up, eight patients with osteoporosis presented new vertebral fractures (12\%) and new spinal metastases appeared in two oncological patients (5\%).

Perez-Higueras et $\mathrm{a}^{27}$ prospectively examined 13 patients who had undergone $27 \mathrm{PVs}$ and a minimum of five years of follow-up. There was a significant reduction in pain after three days, three months, and five years of follow-up (average of 66 months), with a slight reduction in benefits over the long term when compared to the short term. This occurred particularly in patients with severe osteoporosis and residual kyphosis.

Rousing et $\mathrm{a}^{28}$ accompanied 49 patients with acute (less than two weeks) and subacute (between two and eight weeks) fractures from osteoporosis, 25 of whom had undergone PV and 24 of whom had undergone a non-surgical procedure, over a 12-month period, in a randomized clinical study. Pain was evaluated using a visual analog scale. The degrees of pain before and immediately following PV were 7.9 and 2.0, respectively. At three months and 12 months of follow-up there were no differences in the pain scale between the groups. They concluded that PV is a good treatment for some patients with acute/subacute pain resulting from osteoporotic vertebral fractures, but that most fractures will heal after 8 to 12 weeks of conservative treatment, with a subsequent decline in pain.

Legroux-Gérot et $a^{29}$ followed up 16 patients who had undergone $21 \mathrm{PVs}$ at least 12 months earlier (average: 35 months) in a prospective study. Significant pain improvement was observed after six months, at one year, and long term, with no significant 
change between one year and the last assessment. Nevertheless, in four patients, the pain had worsened at the last assessment as compared to preoperative levels, when evaluated using the visual numerical pain scale.

Barr et $a /{ }^{30}$ conducted a retrospective study of 38 patients with vertebral fractures who had undergone a total of $70 \mathrm{PVs}$. In 36 patients (95\%) there was significant pain relief within 48 hours following surgery and, of these, 34 patients (94\%) maintained the long-term benefit, with an average of 18 months of follow-up.

Grados et $a^{131}$, evaluating retrospectively the outcomes of 34 PVs in 25 patients with an average follow-up of 48 months (ranging from 12 to 84 months), reported significant reduction after a month of follow-up, with long-term persistence of the benefit and no statistically significant difference between the two evaluation times.

Masala et $a^{\beta 2}$ followed up 285 patients who underwent PV with follow-up at one week, one year, and three years. The results of the study confirmed that PV offers pain reduction (after a period of at least three years of follow-up), with significant immediate clinical improvement, measured at one week, in terms of locomotion and the ability to perform activities of daily living. The results indicate that one week after treatment, all patients had a significant reduction in pain. Pain relief remained stable during the follow-up period, offering a better quality of life. Another observation that can be made from the results is that outcomes from PV were better in patients aged under 75 years than in older patients. There was no difference in pain relief between men and women at one week following the procedure, although in the long term, women presented better analgesic results after three years. Thirty-two percent of the patients had been bedridden or using wheelchairs, and $60 \%$ had experienced pain when walking due to vertebral fracture prior to the PV. Almost all patients complained of inability or difficulty in performing activities of daily living because of moderate or severe pain, and $98 \%$ used analgesic drugs. One week following vertebroplasty, all the patients reported walking normally (with or without pain) and more than $95 \%$ were able to perform daily activities without pain or with mild pain. The patients also presented a significant reduction in drug therapy for pain. Another important parameter of the study was that even 1-3 years after treatment, these results were still valid. Pain reduction and a marked improvement in functional state following treatment were consistently reported across all age groups, regardless of the number of vertebral fractures treated. The fact that most patients who underwent PV said they would be willing to do it again is perhaps the best indication of the success and acceptance of this technique. ${ }^{32}$

Although several studies report the benefits of PV, some studies demonstrate outcomes similar to those of conservative treatment.

Buchinder et $a^{33}$ conducted a multicenter, randomized, double-blind, placebo-control group study involving 78 participants (35 out of 38 in the vertebroplasty group and 36 out of 40 in the placebo group), which showed outcomes in favor of PV only within the first 24 postoperative hours. At six weeks, six months, and 12 months after surgical treatment, the pain profile was similar to that of patients who underwent conservative treatment. They concluded that there are no significant benefits from vertebroplasty in the treatment of painful osteoporotic vertebral fractures at one week, one month, three months, or six months after treatment, and that its use is questionable. The author herself recognizes a significant bias in regard the number of patients who refused to participate in the study.

Kalmmes et $\mathrm{a}^{34}$ conducted a randomized multicenter study with 131 patients with from one to three osteoporotic fractures. Sixty-eight patients underwent vertebroplasty. Sixty-three underwent a procedure similar to vertebroplasty but without the injection of PMMA into the vertebral body. All patients were exposed to the odor of PMMA. The two study groups had substantial immediate improvements in disability and pain (three days) following the procedure, with similar improvement in both groups. The improvement noted in each group within the first 72 postoperative hours was maintained for one month, with no differences between them. These results suggest that factors other than the application of PMMA may contri- bute to clinical improvement following vertebroplasty. Such factors may include the effect of the local anesthesia, in addition to other non-specific effects, such as the expectation of pain relief (placebo effect) and the natural history of the fracture. In conclusion, after one month, the clinical improvements in patients with painful osteoporotic vertebral fractures were similar between those treated with vertebroplasty and those treated with a simulated process.

The complications described are bleeding at the site of the puncture (generally resolved with simple compression of the site); temporary worsening of the pain and fever as a reaction to the temperature generated by the polymerization of the biomaterial; infection; injury of nerve roots or spinal cord due to improper contrast leakage, with a potential risk of paralysis and/or radiculopathy; CSF leak; leakage of biomaterial into the venous system with pulmonary embolism. Such complications can be easily avoided with proper patient selection, preliminary care, radioscopic control of the injection, and proper training of the surgical team. ${ }^{11,14}$ Trout et $a / 35$ reported that the relative risk of developing a new fracture at a level adjacent to the vertebroplasty is 4.62 times higher than at a non-adjacent level.

Tseng et $a^{\beta 6}$ followed up 852 patients (1131 vertebroplasties) over a period of six years, and concluded that the average time for a fracture of a vertebral body adjacent to the PV is 71.9 days and that non-adjacent fractures occur at around 289 days following the PV.

Syed et $a l,{ }^{37}$ in a retrospective analysis of 253 women with initial diagnoses of vertebral fractures from osteoporosis, concluded that one fifth of patients will develop a new vertebral fracture within a year following vertebroplasty. Once a patient seeks medical care for an osteoporotic vertebral fracture, even with conventional conservative treatment, the patient has a significantly higher risk of presenting another fracture of a vertebral body within a year. It appears that once an osteoporotic fracture of a vertebral body occurs, the clinical evolution of refracture is more likely. ${ }^{38}$ One patient presented intense pain symptoms in the eighth month following the PV resulting from a fracture of the adjacent vertebral body. Other possible complications have not been encountered in our patients so far.

Some authors have postulated that PV could increase the incidence of fractures in adjacent vertebrae. ${ }^{31,39}$ It is widely accepted that the alignment and physiological maintenance of the spine is important to minimize the acceleration of degeneration at the adjacent level. ${ }^{40,41}$ After vertebroplasty, patients have an increased risk of the appearance of new fractures at adjacent levels and, when these fractures occur, they occur earlier than fractures at non-adjacent levels. ${ }^{35,42}$

Conservative treatment that submits the elderly patient to prolonged immobilization poses potential risks such as deep vein thrombosis, pneumonia, and loss of bone density.

Furthermore, despite having strong clinical evidence, the various case study reports should be considered as indicative of the efficacy of PV.

It is important to emphasize the therapeutic indication for patients who show improvement with conservative treatment, and the need for pain relief, even if short term, for rehabilitation focused on avoiding the risks of immobilization in elderly patients.

In contrast to the studies that do not demonstrate the efficacy of $\mathrm{PV}$ in relation to conservative treatment, and despite their use of advanced scientific methodology, we believe that they are biased by selection

\section{CONCLUSION}

Despite the small sample size and short follow-up period, the PV outcomes were satisfactory in terms of offering relief from painful symptoms, and safe in terms of the risk of complications, improving patients' quality of life and significantly reducing their use of analgesics.

All authors declare no potential conflict of interest concerning this article. 


\section{REFERENCES}

1. Masala S, Lunardi P, Fiori R, Liccardo G, Massari F, Ursone A, et al. Vertebroplasty and kyphoplasty in the treatment of malignant vertebral fractures. J Chemother. 2004;16(Suppl 5):30-3

2. Watts NB. Osteoporotic vertebral fractures. Neurosurg Focus. 2001;10(4):E12.

3. Wu SS, Lachmann E, NaglerW. Current medical, rehabilitation, and surgical management of vertebral compression fractures. J Womens Health (Larchmt). 2003;12(1):17-26.

4. Lyles KW, Gold DT, Shipp KM, Pieper CF, Martinez S, Mulhausen PL. Association of osteoporotic vertebral compression fractures with impaired functional status. Am J Med. 1993:94(6):595-601.

5. Ross PD, Davis JW, Epstein RS, Wasnich RD. Pain and disability associated with new vertebral fractures and other spinal conditions. J Clin Epidemiol. 1994;47(3):231-9.

6. Bidwood G. Understanding osteoporosis and its treatment. New York: Parthenon; 1996.

7. Bostrom MP, Lane JM. Future directions. Augmentation of osteoporotic vertebral bodies. Spine (Phila Pa 1976). 1997;22(Suppl 24):38-42.

8. Amar AP, Larsen DW, Esnaashari N, Albuquerque FC, Lavine SD, Teitelbaum GP. Percutaneous transpedicular polymethylmethacrylate vertebroplasty for the treatment of spinal compression fractures. Neurosurgery. 2001;49(5):1105-14;

9. Deramond H, Depriester C, Galibert P, Le Gars D. Percutaneous vertebroplasty with polymethylmethacrylate. Technique, indications, and results. Radiol Clin North Am. 1998;36(3):533-46.

10. Galibert $P$, Deramond $H$, Rosat $P$, Le Gars D. Preliminary note on the treatment of vertebral angioma by percutaneous acrylic vertebroplasty. Neurochirurgie. 1987:33(2):166-8.

11. Kaufmann TJ, Jensen ME, Schweickert PA, Marx WF, Kallmes DF. Age of fracture and clinical outcomes of percutaneous vertebroplasty. AJNR Am J Neuroradiol. $2001 ; 22(10): 1860-3$

12. Hübner A, Lauda F, Lima E, Dani W,Israel C. Comparação da resistência do corpo vertebral pré e pós vertebroplastia. Estudo experimental em vértebras e suínos. Coluna/ Columna. 2004;3(2):82:6.

13. Pinto R, Matos R, Neves N, Tulhas JM, Cabarl AT, Almeida L. A vertebroplastia no tratamento das fraturas vertebrais osteoporóticas dolorosas. Coluna/Columna. 2007;6(3):136-4

14. Barbero S, Casorzo I, Durando M, Mattone G, Tappero C, Venturi C, et al. Percutaneous vertebroplasty: the follow-up. Radiol Med. 2008;113(1):101-13.

15. Baroud G, Bohner M. Biomechanical impact of vertebroplasty. Postoperative biomechanics of vertebroplasty. Joint Bone Spine. 2006;73(2):144-50.

16. Dean JR, Ison KT, Gishen P. The strengthening effect of percutaneous vertebroplasty. Clin Radiol. 2000;55(6):471-6.

17. McGraw JK, Cardella J, Barr JD, Mathis JM, Sanchez O, Schwartzberg MS, et al. SIR Standards of Practice Committee. Society of Interventional Radiology quality improvement guidelines for percutaneous vertebroplasty. J Vasc Interv Radiol. 2003;14(7):827-31.

18. Leech JA, Dulberg C, Kellie S, Pattee L, Gay J. Relationship of lung function to severity of osteoporosis in women. Am Rev Respir Dis. 1990:141(1):68-71.

19. Weill A, Chiras J, Simon JM, Rose M, Sola-Martinez T, Enkaoua E. Spinal metastases: indications for and results of percutaneous injection of acrylic surgical cement. Radiology. 1996:199(1):241-7.

20. Lieberman IH, Dudeney S, Reinhardt MK, Bell G. Initial outcome and efficacy of "kyphoplasty" in the treatment of painful osteoporotic vertebral compression fractures. Spine (Phila Pa 1976). 2001;26(14):1631-8.

21. Jensen ME, Evans AJ, Mathis JM, Kallmes DF, Cloft HJ, Dion JE. Percutaneous polymethylmethacrylate vertebroplasty in the treatment of osteoporotic vertebral body compression fractures: technical aspects. AJNR Am J Neuroradiol. 1997;18(10):1897-904.

22. Karlsson MK, Hasserius R, Gerdhem P, Obrant KJ, Ohlin A. Vertebroplasty and kyphoplasty: New treatment strategies for fractures in the osteoporotic spine. Acta Orthop. 2005;76(5):620-7.

23. McGraw JK, Lippert JA, Minkus KD, Rami PM, Davis TM, Budzik RF. Prospective evaluation of pain relief in 100 patients undergoing percutaneous vertebroplasty: results and follow-up. J Vasc Interv Radiol. 2002;13(9):883-6.

24. Rodriguez-Catarino M. Percutaneous vertebroplasty--a new method for alleviation of back pain. Lakartidningen. 2002;99(9):882-90

25. Hochmuth K, Proschek D, Schwarz W, Mack M, Kurth AA, Vogl TJ. Percutaneous vertebroplasty in the therapy of osteoporotic vertebral compression fractures: a critical review. Eur Radiol. 2006;16(5):998-1004

26. Pizzoli AL, Brivio LR, Caudana R, Vittorini E. Percutaneous CT-guided vertebroplasty in the management of osteoporotic fractures and dorsolumbar metastases. Orthop Clin North Am. 2009;40(4):449-58.

27. Pérez-Higueras A, Alvarez L, Rossi RE, Quiñones D, Al-Assir I. Percutaneous vertebroplasty: Iong-term clinical and radiological outcome. Neuroradiology. 2002;44(11):950-4.

28. Rousing R, Hansen KL, Andersen MO, Jespersen SM, Thomsen K, Lauritsen JM. Twelvemonths follow-up in forty-nine patients with acute/semiacute osteoporotic vertebral fractures treated conservatively or with percutaneous vertebroplasty: a clinical randomized study. Spine (Phila Pa 1976). 2010;35(5):478-82.

29. Legroux-Gérot I, Lormeau C, Boutry N, Cotten A, Duquesnoy B, Cortet B. Long-term follow-up of vertebral osteoporotic fractures treated by percutaneous vertebroplasty. Clin Rheumatol. 2004;23(4):310-7.

30. Barr JD, Barr MS, Lemley TJ, McCann RM. Percutaneous vertebroplasty for pain relief and spinal stabilization. Spine (Phila Pa 1976). 2000;25(8):923-8.

31. Grados F, Depriester C, Cayrolle G, Hardy N, Deramond H, Fardellone P. Long-term observations of vertebral osteoporotic fractures treated by percutaneous vertebroplasty. Rheumatology (Oxford). 2000;39(12):1410-4.

32. Masala S, Mammucari M, Angelopoulos G, Fiori R, Massari F, Faria S, et al. Percutaneous vertebroplasty in the management of vertebral osteoporotic fractures. Short-term, midterm and long-term follow-up of 285 patients. Skeletal Radiol. 2009;38(9):863-9.

33. Buchbinder R, Osborne RH, Ebeling PR, Wark JD, Mitchell P, Wriedt C, et al. A randomized trial of vertebroplasty for painful osteoporotic vertebral fractures. N Engl J Med. 2009:361(6):557-68.

34. Kallmes DF, Comstock BA, Heagerty PJ, Turner JA, Wilson DJ, Diamond TH, et al. A randomized trial of vertebroplasty for osteoporotic spinal fractures. N Engl J Med. 2009:361(6):569-79

35. Trout AT, Kallmes DF, Kaufmann TJ. New fractures after vertebroplasty: adjacent fractures occur significantly sooner. AJNR Am J Neuroradiol. 2006;27(1):217-23.

36. Tseng YY, Yang TC, Tu PH, Lo YL, Yang ST. Repeated and multiple new vertebral compression fractures after percutaneous transpedicular vertebroplasty. Spine (Phila Pa 1976). 2009;34(18):1917-22.

37. Syed MI, Patel NA, Jan S, Harron MS, Morar K, Shaikh A. New symptomatic vertebral compression fractures within a year following vertebroplasty in osteoporotic women. AJNR Am J Neuroradiol. 2005;26(6):1601-4.

38. Lindsay R, Silverman SL, Cooper C, Hanley DA, Barton I, Broy SB, et al. Risk of new vertebral fracture in the year following a fracture. JAMA. 2001;285(3):320-3

39. Uppin AA, Hirsch JA, Centenera LV, Pfiefer BA, Pazianos AG, Choi IS. Occurrence of new vertebral body fracture after percutaneous vertebroplasty in patients with osteoporosis. Radiology. 2003;226(1):119-24.

40. Rohlmann A, Zander T, Bergmann G. Spinal loads after osteoporotic vertebral fractures treated by vertebroplasty or kyphoplasty. Eur Spine J. 2006;15(8):1255-64.

41. Oda I, Cunningham BW, Buckley RA, Goebel MJ, Haggerty CJ, Orbegoso CM, et al. Does spinal kyphotic deformity influence the biomechanical characteristics of the adjacent motion segments? An in vivo animal model. Spine (Phila Pa 1976). 1999:24(20):2139-46.

42. Klotzbuecher CM, Ross PD, Landsman PB, Abbott TA 3rd, Berger M. Patients with prior fractures have an increased risk of future fractures: a summary of the literature and statistical synthesis. J Bone Miner Res. 2000;15(4):721-39. 